\title{
Ketone Body Utilization and Its Metabolic Effect in Resting Muscles of Normal and Streptozotocin-Diabetic Rats
}

\author{
YUKICHI OKUDA, KoICHI KAWAI, HAJIME OHMORI*, AND \\ KAMEJIRO YAMASHITA \\ Department of Internal Medicine, Institute of Clinical Medicine, \\ University of Tsukuba, Ibaraki 305, and *Department of Health \\ and Physical Education, Faculty of General Education, Tokyo \\ University of Agriculture and Technology, Fuchu, Tokyo 183, \\ Japan
}

\begin{abstract}
By using an in situ rat hindquarter perfusion, we evaluated ketone body utilization and its metabolic effects in the resting muscle of $24 \mathrm{~h}$ fasted normal and streptozotocin (STZ)-diabetic rats. Under the perfusion with ketone body-supplementation ( $1 \mathrm{mM}$ each of acetoacetic acid (AcAc) and 3-hydroxybutyric acid (3-OHB)), the AcAc and 3-OHB uptake of STZ-diabetic rats was significantly $(\mathrm{P}<0.05)$ smaller than that of normal rats. This might be explained by the low enzyme activity of 3-oxoacid CoA transferase demonstrated in the hindlimb muscles of STZ-diabetic rats and this reduced ketone body uptake would be one of the causes of the development of diabetic ketoacidosis. The glucose uptake and the phosphofructokinase $(\mathrm{PFK})$ activity of normal rats were significantly $(\mathrm{P}<0.05)$ higher than those of STZ-diabetic rats. In both normal and STZ-diabetic rats, the glucose utilization and PFK activity of the muscles in the ketone body-supplemented condition were significantly $(\mathrm{P}<0.05)$ lower than those in the non-supplemented condition. This inhibition of glucose utilization by ketone bodies should be due to the mechanism by which the oxidation of ketone bodies inhibits PFK in the muscle.
\end{abstract}

Key words: Ketone body, Rat hindquarter perfusion, Streptozotocin diabetic rats, 3-Oxoacid CoA transferase, Phosphofructokinase.

(Endocrinol Japon 38: 245-251, 1991)

KETONE bodies are oxidized in extra-hepatic tissues such as skeletal muscles, cardiac muscle, brain and kidney, and are a very important fuel in the prolonged fasting state [1]. However, there are few reports which have dealt with ketone body metabolism in peripheral tissues such as skeletal muscles. Previous studies concerning ketone body metabolism in muscles have been performed by using an isolated diaphragma [2], or soleus muscle [3]. However, more physiological and serious studies are needed to clarify ketone body metabolism in normal and diabetic muscles. We therefore evaluated the resting muscle's ketone body and

Received: June 29, 1990

Accepted: March 20, 1991

Correspondence to: Dr. Yukichi OKUDA, Institute of Clinical Medicine, University of Tsukuba, Tsukuba-shi, Ibaraki 305, Japan. glucose utilization by means of an in situ hindquarter perfusion technique in both normal and STZ-diabetic rats.

\section{Materials and Methods}

\section{Animals}

Male Wistar rats were obtained from Dōken Experimental Animal Co. (Ibaraki, Japan). A mild diabetic state was induced at 6 weeks of age by injecting STZ (25 mg/kg, Upjohn Co., USA), dissolved in $300 \mu l$ of citrate buffer $(\mathrm{pH} 4.5)$ into a tail vein of $24 \mathrm{~h}$ fasted rats.

\section{Hindquarter perfusion}

Both normal and STZ-diabetic rats were used 
for this experiment under pentobarbital anesthesia $(50 \mathrm{mg} / \mathrm{kg}$, i.p.). Perfusion of the isolated rat hindquarter was carried out according to the method described by Chan and Dehaye [4]. The standard medium used for perfusion was composed of a Krebs-Henseleit bicarbonate buffer (KHB buffer, $\mathrm{pH}$ 7.4) oxygenated with 95\% $\mathrm{O}_{2}-5 \% \mathrm{CO}_{2}$ containing 3\% Dextran T-70 (Pharmacia Fine Chemicals, Uppsala, Sweden), human erythrocytes washed with $0.9 \% \mathrm{NaCl}$ solution and KHB buffer, and $5.5 \mathrm{mM}$ glucose. After the hindlimb had been washed out with $50 \mathrm{ml}$ of oxygenated KHB buffer, the rat was placed in the perfusion apparatus, based on a modification of the Miller-Mortimore model [5], and the hindlimb was perfused at a flow rate of $4 \mathrm{ml} / \mathrm{min}$ with $85 \mathrm{ml}$ of recirculating perfusate. After pre-perfusion with the perfusate described above for $20 \mathrm{~min}$ at $37^{\circ} \mathrm{C}$, the tissue was then perfused either with the KHB buffer added $1 \mathrm{mM}$ AcAc, $1 \mathrm{mM} 3-\mathrm{OHB}$ and $10 \mu \mathrm{U} / \mathrm{ml}$ regular insulin (ketone bodysupplemented condition, each value being the final concentration) or with KHB buffer added only $10 \mu \mathrm{U} / \mathrm{m} l$ regular insulin (ketone body nonsupplemented conditon). After pre-perfusion for a further $5 \mathrm{~min}, 0.4 \mathrm{~m} l$ aliquots of perfusate were collected at $10 \mathrm{~min}$ intervals for $100 \mathrm{~min}$. The samples were placed in chilled tubes and the supernatant obtained by centrifugation at 3000 rpm for 15 min at $4^{\circ} \mathrm{C}$ was stored at $-80^{\circ} \mathrm{C}$ until assayed. For the assay of lactate, $0.3 \mathrm{~m} l$ aliquots of perfusate were also collected at $0 \mathrm{~min}, 40 \mathrm{~min}, 60$ min and $90 \mathrm{~min}$ in chilled tubes containing $0.6 \mathrm{M}$ $\mathrm{HClO}_{4}$. After the perfusion, the perfused hindlimb muscles were weighed and the glucose and ketone body uptake was expressed as values per muscle weight. In order to evaluate the uptake of ketone bodies and glucose by erythrocytes in the perfusion medium, perfusate containing $1 \mathrm{mM}$ AcAc, $1 \mathrm{mM} 3-\mathrm{OHB}, 5.5 \mathrm{mM}$ glucose and 10 $\mu \mathrm{U} / \mathrm{m} l$ regular insulin was circulated in the perfusion apparatus without passing the hindlimb.

\section{Preparation of tissue extracts}

After perfusion, red portions of gastrocnemius muscle were obtained by the method of Hagg et al. [6] and stored for 1-3 days in liquid $N_{2}$. Thereafter, the muscle was pulverized in a mortar under liquid $\mathrm{N}_{2}$ and used for determination of enzyme activities of 3-oxoacid CoA transferase and phosphofructokinase (PFK).

\section{Sample analysis}

The plasma and perfusate glucose concentration was measured by a glucose oxidase method (glucose analyzer 2, Beckman Instruments, Fullerton, CA, USA). Plasma and perfusate AcAc, 3-OHB and total ketone body (TKB) concentrations were determined by the method of Harano $e t$ al. [7] (Ketone test ${ }^{\circledR}$, Sanwa Kagaku Co., Nagoya, Japan). 3-OHB was calculated by subtracting the AcAc value from the TKB value. The lactate concentration in the perfusate was determined with a commercial kit (Lactate-UV-test ${ }^{\circledR}$, Boehringer-Mannheim, Mannheim, Germany). The plasma immunoreactive insulin (IRI) concentration was determined by a radioimmunoassay (RIA) according to the method of Herbert et al. [8].

\section{Determination of enzyme activities}

After small slices were removed from the frozen tissue, the tissue $(10 \mathrm{mg})$ was weighed rapidly, and homogenization was begun on the still frozen tissue, so that thawing occurred during tissue disintegration. In both cases, $1 \mathrm{ml}$ chilled homogenization medium $[0.25 \mathrm{M}$ sucrose, $1 \mathrm{mM}$ 2-mercaptoethanol, $10 \mathrm{mM}$ Tris-HCl buffer $(\mathrm{pH}$ 7.4) for 3-oxoacid CoA transferase; $150 \mathrm{mM} \mathrm{KCl}$, $50 \mathrm{mM} \mathrm{KHCO}, 6 \mathrm{mM}$ EDTंA for PFK] was used. The tissues were homogenized with a glass pestle driven by a low-speed motor, and then centrifuged for $20 \mathrm{~min}$ at $30000 \mathrm{~g}$. Enzyme determinations were made on this supernatant fluid (enzyme sample). 3-Oxoacid CoA transferase activity was determined as the rate of acetoacetyl-CoA formation from succinyl-CoA and acetoacetate by the method of Williamson et al. [9]. Namely, the silica cuvettes $(1 \mathrm{~cm})$ contained in a final volume of $2 \mathrm{ml}$ : Tris-HCl buffer, pH $8.5(100 \mu \mathrm{mol}), \mathrm{MgCl}_{2}(10$ $\mu \mathrm{mol})$, iodoacetamide $(10 \mu \mathrm{mol})$ (to inhibit acetoacetyl CoA thiolase and enzymes of the hydroxymethylglutaryl-CoA pathway) and succinyl-CoA $(0.2 \mu \mathrm{mol})$. The enzyme sample $(0.1 \mathrm{ml})$ was added and the rate of increase in extinction at $313 \mathrm{~nm}$ was measured for $2 \mathrm{~min}$ at $25^{\circ} \mathrm{C}$. Under these assay conditions the millimolar extinction coefficient of the acetoacetyl-CoA- $\mathrm{Mg}^{2+}$ complex was found to be $12(313 \mathrm{~nm})$. PFK activity was determined by the method of Shonk and Boxer [10]. Namely, the silica cuvettes $(1 \mathrm{~cm})$ contained in a final volume of $3.54 \mathrm{ml}: 3.0 \mathrm{ml}$ buffer [Triethanolamine $(50 \mathrm{mM})$, EDTA (5 mM), pH 7.6], $\mathrm{MgCl}_{2}(10 \mathrm{mM})$, Aldolase (1.0 U), $\alpha$-glycerolphosphate dehydrogenase (7.1 
$\mathrm{U})$-triosephosphate isomerase (18.3 U) mixture, $\mathrm{NADH}(0.3 \mathrm{mM})$ and ATP $(2.8 \mathrm{mM})$.

After the enzyme sample $(0.02 \mathrm{ml})$ was added, the absorbance at $340 \mathrm{~nm}$ was briefly recorded, the enzyme reaction was initiated by the addition of the substrate, fructose- 6 -phosphate $(2.8 \mathrm{mM})$. The rate of increase in extinction at $340 \mathrm{~nm}$ was measured for $2 \mathrm{~min}$ at $25^{\circ} \mathrm{C}$. Under these assay conditions the millimolar extinction coefficient was found to be $6.3(340 \mathrm{~nm})$. All chemicals were of reagent grade and obtained from local suppliers.

\section{Statistics}

Data were analyzed by analysis of variance followed by group comparisons (Student's $t$ test) when a significant F-value was obtained, and $\mathrm{p}<0.05$ was considered to be significant. All data in this paper are expressed as the mean \pm SEM.

\section{Results}

Comparison of plasma ketone bodies, glucose and insulin levels in normal and STZ-diabetic rats (Table 1)

In a $24 \mathrm{~h}$ fasted state, the plasma glucose and total ketone body (AcAc $+3-\mathrm{OHB})$ concentrations of STZ-diabetic rats were significantly higher than those of normal rats. $(300 \pm 29 \mathrm{mg} / \mathrm{d} l$ vs. $96 \pm 10$ $\mathrm{mg} / \mathrm{d} l, 1242 \pm 40 \mu \mathrm{M}$ vs. $818 \pm 46 \mu \mathrm{M}, \mathrm{p}<0.05)$. The insulin concentration of STZ-diabetic rats was significantly lower than that of normal rats $(8 \pm 3$ $\mu \mathrm{U} / \mathrm{m} l$ vs. $16 \pm 4 \mu \mathrm{U} / \mathrm{m} l, \mathrm{p}<0.05)$.

Ketone body uptake by perfused hindquarter of $24 \mathrm{~h}$ fasted normal and STZ-diabetic rats (Fig. 1)

Figure 1 shows the changes in the ketone body concentrations of the perfusate in normal and STZ-diabetic rats under the ketone bodysupplemented perfusate condition. The basal values of TKB, AcAc and 3-OHB were $1954 \pm 47$, $969 \pm 26,982 \pm 44 \mu \mathrm{mol} / l$ in normal rats, and
$1964 \pm 36,974 \pm 38,984 \pm 62 \mu \mathrm{mol} / l$ in $\mathrm{STZ}$ diabetic rats, respectively. No significant difference was observed between normal and STZdiabetic rats in these values.

TKB and AcAc concentrations in the perfusate were gradually decreased during the perfusion in both normal and STZ-diabetic rats and a significant decrease was observed $50 \mathrm{~min}$ after the perfusion. On the other hand, there was no significant change in the $3-\mathrm{OHB}$ concentration in either normal or STZ-diabetic rats. Also, no significant change was observed in the ketone body levels during the control experiment (manipulation without muscle perfusion). The cumulative TKB and AcAc uptake by perfused hindquarter in the normal rats were significantly greater than those in the STZ-diabetic rats $(\mathrm{p}<0.05)$ (Table 2). The AcAc uptake by perfused hindquarter was significantly greater than the $3-\mathrm{OHB}$ uptake in both normal and STZ-diabetic rats $(p<0.05)$ (Table 2). The ketone body concentrations of perfusate in both normal and STZ-diabetic rats under the ketone body non-supplemented condition were undetectable.

Glucose uptake by perfused hindquarter of $24 \mathrm{~h}$ fasted normal and STZ-diabetic rats (Figs. 2, 3)

Figure 2 shows the time course of glucose concentrations of perfusate in both ketone bodysupplemented and non-supplemented conditions. The glucose concentration in the perfusate began to elicit a significant decrease $(\mathrm{p}<0.05)$ at a sampling time of $40 \mathrm{~min}$ and $60 \mathrm{~min}$ in the non-supplemented experiment and supplemented experiment, respectively. The glucose concentration in the non-supplemented experiment was significantly lower than that in the supplemented experiment after $50 \mathrm{~min}$ of perfusion. The cumulative glucose uptake by perfused hindquarter in the non-supplemented experiment was significantly greater than that in the supplemented

Table 1. Plasma ketone body, glucose and insulin levels of normal and STZ-diabetic rats

\begin{tabular}{|c|c|c|c|c|c|c|}
\hline & \multirow[b]{2}{*}{$\mathrm{N}$} & \multicolumn{3}{|c|}{ Plasma ketone body $(\mu \mathrm{M})$} & \multirow{2}{*}{$\begin{array}{l}\text { Plasma glucose } \\
\qquad(\mathrm{mg} / \mathrm{d} l)\end{array}$} & \multirow{2}{*}{$\begin{array}{l}\text { Plasma insulin } \\
\qquad(\mu \mathrm{U} / \mathrm{m} l)\end{array}$} \\
\hline & & AcAc & $3-\mathrm{OHB}$ & Total & & \\
\hline Normal rats & 14 & $240 \pm 18$ & $574 \pm 49$ & $818 \pm 46$ & $96 \pm 10$ & $16 \pm 4$ \\
\hline STZ-diabetic rats & 14 & $326 \pm 31 *$ & $932 \pm 74^{*}$ & $1242 \pm 40^{*}$ & $300 \pm 29 * *$ & $8 \pm 3^{*}$ \\
\hline
\end{tabular}

Values are mean \pm SEM.

$* ; \mathrm{p}<0.05$ and $* * ; \mathrm{p}<0.01$, Normal vs. STZ-diabetic rats. 

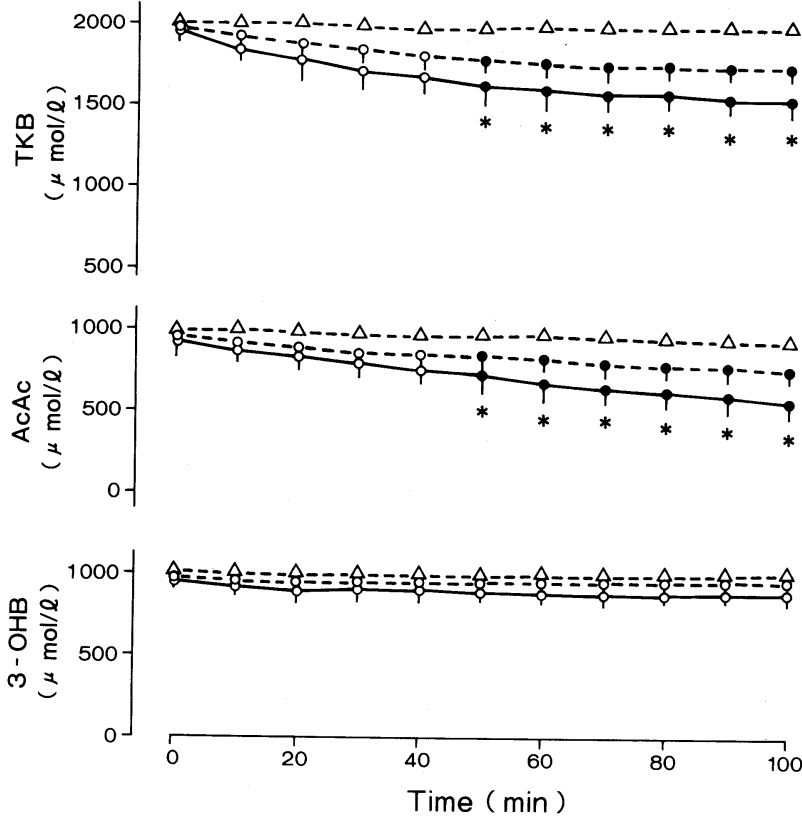

Fig. 1. Changes in ketone body concentrations of perfusate during in situ hindlimb-muscle perfusion in normal and STZ-diabetic rats. After 25 min of pre-perfusion, aliquots of perfusate were collected to determine ketone body levels every $10 \mathrm{~min}$.

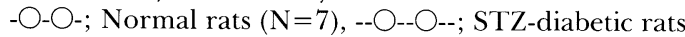
$(\mathrm{N}=7),--\triangle-\triangle--;$ control experiment $(\mathrm{N}=5)$. Results are expressed as the mean \pm SEM. *; $\mathrm{p}<0.05$ normal vs STZ-diabetic rats, $\mathrm{p}<0.05$ vs. Basal values $(0 \mathrm{~min})$. experiment $(\mathrm{p}<0.05)$ (Table 2). Similar results were obtained with STZ-diabetic rats (Fig. 3, Table 2). Namely, the glucose concentration in the perfusate began to show a significant decrease $(p<0.05)$ at a sampling time of $100 \mathrm{~min}$ and 70 min in the non-supplemented experiment and supplemented experiment, respectively (Fig. 3). The glucose concentration in the nonsupplemented experiment was significantly lower than that in the ketone body-supplemented experiment after $70 \mathrm{~min}$ of purfusion. The cumulative glucose uptake by perfused hindquarter in the non-supplemented experiment was significantly greater than that in the supplemented experiment $(\mathrm{p}<0.05)$ (Table 2). The lactate level of perfusate during the experiment was similar to those found in previous perfusion studies [11-13].

Comparison of 3-oxoacid CoA transferase and phosphofructokinase activity in hindlimb muscles in normal and STZ-diabetic rats (Table 3)

3-Oxoacid CoA transferase activity in hindlimb muscles perfused in the ketone body supplemented condition was significantly higher than that of hindlimb muscles perfused in the nonsupplemented condition $(\mathrm{p}<0.05)$ in both normal and diabetic rats. In addition, the 3-oxoacid CoA transferase activity of STZ-diabetic rats was significantly lower than that of normal rats in both ketone body supplemented and non-supplemented conditons $(\mathrm{p}<0.05)$.

Table 2. Summary of data obtained from the rat hindlimb-muscle perfusion

\begin{tabular}{|c|c|c|c|c|}
\hline \multirow[b]{2}{*}{ Ketone body } & \multicolumn{2}{|c|}{ Normal rats } & \multicolumn{2}{|c|}{ STZ-diabetic rats } \\
\hline & $\begin{array}{l}\text { Non-supplemented } \\
\qquad(\mathrm{N}=7)\end{array}$ & $\begin{array}{l}\text { Supplemented } \\
\qquad(\mathrm{N}=7)\end{array}$ & $\begin{array}{l}\text { Non-supplemented } \\
\qquad(\mathrm{N}=7)\end{array}$ & $\begin{array}{l}\text { Supplemented } \\
\qquad(\mathrm{N}=7)\end{array}$ \\
\hline Fasting body wt (g) & $225 \pm 20$ & $238 \pm 16$ & $174 \pm 19$ & $170 \pm 21$ \\
\hline Hindimb muscle weight (g) & $24.3 \pm 2.1$ & $25.0 \pm 2.6$ & $16.1 \pm 3.2 \dagger$ & $15.9 \pm 2.7 \dagger$ \\
\hline $\begin{array}{l}\text { TKB uptake } \\
(\mu \mathrm{mol} / 100 \mathrm{~min} / \mathrm{g} \text { muscle })\end{array}$ & - & $1.78 \pm 0.29$ & - & $1.01 \pm 0.11 \dagger$ \\
\hline $\begin{array}{l}\text { AcAc uptake } \\
(\mu \mathrm{mol} / 100 \mathrm{~min} / \mathrm{g} \text { muscle })\end{array}$ & - & $1.66 \pm 0.16$ & - & $0.95 \pm 0.05 \dagger$ \\
\hline $\begin{array}{l}\text { 3-OHB uptake } \\
(\mu \mathrm{mol} / 100 \mathrm{~min} / \mathrm{g} \text { muscle })\end{array}$ & - & $0.12 \pm 0.04$ & - & $0.06 \pm 0.02$ \\
\hline $\begin{array}{l}\text { Glucose uptake } \\
(\mu \mathrm{mol} / 100 \mathrm{~min} / \mathrm{g} \text { muscle })\end{array}$ & $3.56 \pm 0.26^{*}$ & $2.34 \pm 0.36$ & $1.80 \pm 0.16^{* \dagger}$ & $1.42 \pm 0.29 \dagger$ \\
\hline
\end{tabular}

Values are mean \pm SEM.

$\dagger \mathrm{p}<0.05$ normal vs. STZ-diabetic rats.

* $\mathrm{p}<0.05$ ketone body-supplemented experiment vs. non-supplemented experiment. 


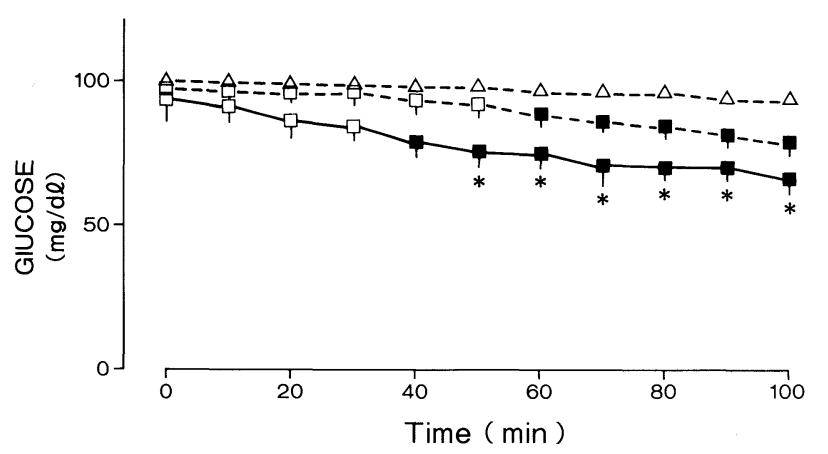

Fig. 2. Changes in glucose concentration of perfusate during in situ hindlimb-muscle perfusion in normal rats. -- $\square--\square--;$ ketone body $(+)(\mathrm{N}=7),-\square-\square-$; ketone body $(-)(\mathrm{N}=7),--\triangle--\triangle--;$ control experiment $(\mathrm{N}=5)$. Results are expressed as the mean \pm SEM.

*; $\mathrm{p}<0.05$ ketone body (+) vs. ketone body (-) - $\mathrm{p}<0.05$ vs. Basal values $(0 \mathrm{~min})$.

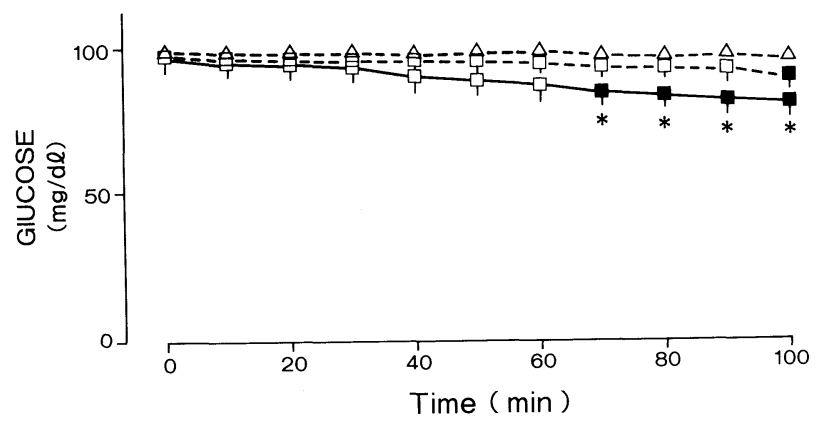

Fig. 3. Changes in glucose concentration of perfusate during in situ hindlimb-muscle perfusion in STZ-diabetic rats. Mean \pm SEM, $N=7$ Results are expressed as the mean \pm SEM -- $\square--\square--;$ ketone body $(+)(\mathrm{N}=7), \quad-\square-\square-$; ketone body $(-)(\mathrm{N}=7),--\triangle--\triangle--;$ control experiment $(\mathrm{N}=5) * ; \mathrm{p}<0.05$ ketone body $(+)$ vs. ketone body $(-) \mathbf{p}<0.05$ vs. Basal values $(0 \mathrm{~min})$.
The PFK activity of hindlimb muscles perfused in the ketone body-supplemented condition was significantly lower than that in the nonsupplemented condition $(p<0.05)$ in both normal and diabetic rats. Furthermore, the PFK activity of the STZ-diabetic rats was significantly lower than that of the normal rats in both ketone bodysupplemented and non-supplemented conditions $(\mathrm{p}<0.05)$.

\section{Discussion}

By using an in situ rat hindquarter perfusion, we evaluated the resting muscle's ketone body utilization. AcAc uptake was significantly higher than 3-OHB uptake in both the normal and STZ diabetic rats in the perfusate condition supplemented with $1 \mathrm{mM}$ of both AcAc and 3-OHB. In order to utilize 3-OHB in the muscle, 3hydroxybutyrate dehydrogenase is absolutely necessary. However, this enzyme activity is scarce in the muscle [11] which is the reason why $3-\mathrm{OHB}$ uptake was negligible in this experiment.

3-Oxoacid CoA transferase is the enzyme involved in ketone body utilization in its initial step. Our data indicate that 3-oxoacid CoA transferase activity is induced in the presence of $1 \mathrm{mM} \mathrm{AcAc}$ and 3-OHB (Table 3). This finding was consistent with the report of Williamson et al. [9] stating that 3-oxoacid CoA transferase activity in isolated muscle increased in parallel with the ketone body concentration in the incubation medium.

The ketone body uptake of STZ-diabetic rats was significantly lower than that of normal rats. This result might be explained by the lower 3-oxoacid CoA transferase activity in hindlimb muscles of STZ-diabetic rats (Table 3). Beatty et al.

Table 3. 3-Oxoacid CoA-transferase and PFK activity of hindlimb muscles of normal and STZ-diabetic rats

\begin{tabular}{llcc}
\hline & N & $\begin{array}{c}\text { 3-Oxoacid CoA-transferase activity } \\
(\mu \mathrm{mol} / \mathrm{min} / \mathrm{g} \text { tissue })\end{array}$ & $\begin{array}{c}\text { PFK activity } \\
(\mu \mathrm{mol} / \mathrm{min} / \mathrm{g} \text { tissue })\end{array}$ \\
\hline $\begin{array}{l}\text { Normal rats } \\
\text { ketone body supplemented }\end{array}$ & 7 & $0.34 \pm 0.05^{* \dagger}$ & $10.0 \pm 0.8^{* \dagger}$ \\
$\quad \begin{array}{l}\text { ketone body non-supplemented } \\
\text { STZ-diabetic rats }\end{array}$ & 7 & $0.18 \pm 0.02^{*}$ & $14.1 \pm 2.2 \dagger$ \\
$\quad$ ketone body supplemented & 7 & $0.15 \pm 0.02^{*}$ & $5.1 \pm 2.1^{*}$ \\
ketone body non-supplemented & 7 & $0.11 \pm 0.01$ & $7.6 \pm 0.3$ \\
\hline
\end{tabular}

Values are mean \pm SEM.

$\dagger \mathrm{p}<0.05$ Normal vs. STZ-diabetic rats.

* $\mathrm{p}<0.05$ Ketone body-supplemented experiment vs. non-supplemented experiment. 
reported that insulin promotes ketone body utilization in muscles by activating 3 -oxoacid CoA transferase activity [14]. In diabetic ketoacidosis, hyperketonemia might induce 3-oxoacid CoA transferase activity by itself, but severe hypoinsulinemia should depress ketone body utilization by interrupting the induction of 3-oxoacid CoA transferase. Actually our pre-investigation, without insulin, but maintaining the same protocol (ketone body-supplemented condition) showed that the cumulative TKB uptake were significantly lower than those with insulin addition $(10 \mu \mathrm{U} / \mathrm{ml})$ in both normal and diabetic rats. (TKB $34 \pm 6 \%$ reduction in normal rats, and $42 \pm 8 \%$ reduction in STZ diabetic rats. $\mathrm{N}=4$ in both cases).

Regarding the glucose uptake, the glucose utilization in the ketone body-supplemented condition was significantly lower than that in the non-supplemented condition. Randle et al. hypothesized that ketone bodies spare the oxidation of glucose in muscle by impeding its entry into the cell by inhibiting its phosphorylation to glucose-6-phosphate, and by inhibiting the phosphofructokinase reaction and the oxidative decarboxylation of pyruvate [15]. This hypothesis is supported by our finding that the PFK activity in hindlimb muscles in the ketone bodysupplemented experiment was significantly lower than that of in non-supplemented experiment. In addition, Goodman et al. indicated that the oxidation of ketone bodies caused an increase in the concentration of intracellular citrate or $\mathrm{NADH}$ which in turn inhibits PFK [16]. This effect of ketone bodies in sparing glucose utilization of muscle seems to be a mechanism in which the energy supply for muscles turns to free fatty acid or ketone bodies from glucose.

We observed that the PFK activity of STZdiabetic rats was significantly lower than that of normal rats. Nowadays, fructose-2,6-bisphosphate is thought to be a potential activator of PFK, a key enzyme of glycolysis [7]. Also, it is known that the fructose-2,6-bisphosphate level in muscles is regulated by insulin and tolbutamide [18, 19]. Although we did not examine the fructose-2,6bisphosphate level in muscles in this experiment, the fructose-2,6-bisphosphate level should be low in mild diabetic rats.

In summary, we have clearly demonstrated that AcAc utilization by skeletal muscles decreases in mild diabetic rats and that ketone body utilization causes a reduction of glucose uptake and PKF activtiy.

\section{Acknowledgements}

The authors wish to thank Dr. Kihachi Ohshima for his technical advice. We also express our gratitude to Mrs. Masako Yamazaki for her expert technical assistance. This study was supported partly by a grant for project research from the University of Tsukuba.

\section{References}

1. Foster DW (1984) From glycogen to ketones and back. Diabetes 33: 1189-1199.

2. Wool, IG, Krahl ME (1959) Incorporation of ${ }^{14} \mathrm{C}$-amino acid into protein of isolated diaphragms: an effect of insulin independent of glucose entry. Am J Physiol 196: 961-964.

3. Chaudry IH, Gould MK (1969) Kinetics of glucose uptake in isolated soleus muscle. Biochem Biophys Acta 177: 527-536.

4. Chan TM and Dehaye JP (1981) Hormone regulation of glucose metabolism in the genetically obese-diabetic mouse $(\mathrm{db} / \mathrm{db})$ : glucose metabolism in the perfused hindquarters of lean and obese mice. Diabetes 30: 211-218.

5. Exton JH (1975) The perfused rat liver. In: Hardman JG, O'Malley BW (eds) Methods in Enzymology: Hormone Action Part D, Isolated
Cells, Tissues, and Organ Systems. Academic Press, New York, Vol. 39: 25-36.

6. Hagg SA, Tayler SI, Ruderman NB (1976) Glucose metabolism in perfused skeletal muscle. Biochem J 158: 203-210.

7. Harano Y, Kosugi K, Hyosu T, Uso S, Ichikawa Y, Shigeta Y (1983) Sensitive and simplified method for the differential determination of serum levels of ketone bodies. Clin Chim Acta 123: 327-336.

8. Herbert V, Lau K-S, Gottlieb CW, Bleicher SJ (1965) Coated charcoal immunoassay of insulin. $J$ Clin Endocrinol Metab 25: 1375-1384.

9. Williamson DH, Bates MW, Page MA, Krebs HA (1971) Activities of enzymes involved in acetoacetate utilization in adult mammalian tissues. Biochem J 121: 41-47.

10. Shonk CE, Boxer GE (1964) Enzyme patterns in 
human tissues. I. Methods for the determination of glycolytic enzymes. Cancer Res 24: 709-721.

11. Ruderman NB, Houghton CRS, Hem R (1971) Evaluation of the isolated perfused rat hindquarter for the study of muscle metabolism. Biochem J 124: 639-651.

12. Zorzano A, Balon TW, Goodman MN, Ruderman NB (1986) Additive effects of prior exercise and insulin on glucose and AIB uptake by rat muscle. Am J Physiol 251 (Endocrinol Metab 14): 21-26.

13. Richter EA, Garetto LP, Goodman MN (1982) Muscle glucose metabolism following exercise in the rat: increased sensitivity to insulin. J Clin Invest 69: 785-793.

14. Beatty CH, Marco A, Peterson RD, Bocek RM, Wert ES (1960) Acetoacetic acid metabolism by skeletal muscle fibers from control and diabetic rats. J Biol Chem 235: 2774-2777.

15. Randle PJ, Garland PB, Hales CN, Newshlme EA,
Denton RM, Pogson CI (1966) Interactions of metabolism and the physiological role of insulin. Rec Prog Horm Res 22: 1-44.

16. Goodman MN, Berger M, Ruderman NB (1974) Glucose metabolism in rat skeletal muscle at rest. Effect of starvation, diabetes, ketone bodies and free fatty acids. Diabetes 23: 881-888.

17. Pilkis SJ, El-Maghrabi MR, Pilkis J, Claus TH, Cumming DA (1981) Fructose 2, 6-bisphosphate-a new activator of phosphofructokinase. $J$ Biol Chem 256: 3171-3174.

18. López-Alarcón L, Marcos ML, Guijarro MC, Feliv JE (1986) Tolbutamide raises fructose-2,6diphosphate concentration in rat soleus muscle. IRCS Med Sci 14: 457-458.

19. Matsuda M, Kaku K, Kaneko T (1986) Regulations of muscle fructose 2, 6-bisphosphate levels by sulfonylureas. Endocrinol Japon 33: 913-917. 